\title{
A Hybrid Artificial Grasshopper Optimization (HAGOA) Meta- Heuristic Approach: A Hybrid Optimizer For Discover the Global Optimum in Given Search Space
}

\author{
Brahm Prakash Dahiya \\ Department of Computer Science and Engineering \\ I. K. G. Punjab Technical University, Punjab, India \\ Corresponding author: brahmprakashdahiya@gmail.com \\ Shaveta Rani ${ }^{a}$, Paramjeet Singh ${ }^{b}$ \\ Department of Computer Science and Engineering \\ Giani Zail Singh Campus College of Engineering and Technology, Punjab, India \\ E-mails: agarg_shavy@yahoo.com, bparam2009@yahoo.com \\ (Received October 17, 2018; Accepted December 11, 2018)
}

\begin{abstract}
Meta-heuristic algorithms are used to get optimal solutions in different engineering branches. Here four types of metaheuristics algorithms are used such as evolutionary algorithms, swarm-based algorithms, physics based algorithms and human based algorithms respectively. Swarm based meta-heuristic algorithms are given more effective result in optimization problem issues and these are generated global optimal solution. Existing swarm intelligence techniques are suffered with poor exploitation and exploration in given search space. Therefore, in this paper Hybrid Artificial Grasshopper Optimization (HAGOA) meta-heuristic algorithm is proposed to improve the exploitation and exploration in given search space. HAGOA is inherited Salp swarm behaviors. HAGOA performs balancing in exploitation and exploration search space. It is capable to make chain system between exploitation and exploration phases. The efficiency of HAGOA meta-heuristic algorithm will analyze using 19 benchmarks functions from F1 to F19. In this paper, HAGOA algorithm is performed efficiency analyze test with Artificial Grasshopper optimization (AGOA), Hybrid Artificial Bee Colony with Salp (HABCS), Modified Artificial Bee Colony (MABC), and Modify Particle Swarm Optimization (MPSO) swarm based meta-heuristic algorithms using uni-modal and multi-modal functions in MATLAB. Comparison results are shown that HAGOA meta-heuristic algorithm is performed better efficiency than other swarm intelligence algorithms on the basics of high exploitation, high exploration, and high convergence rate. It also performed perfect balancing between exploitation and exploration in given search space.
\end{abstract}

Keywords- Swarm intelligence (SI), Hybrid artificial grasshopper optimization (HAGOA), Modified artificial bee colony (MABC), Modify particle swarm optimization (MPSO).

\section{Introduction}

Most real-world issues have high complexity, non-linear constraints, interdependencies amongst variables and an oversized solution space. In recent years meta-heuristic algorithms are most commonly used in engineering application (Gogna and Tayal, 2013). The utilization of a method that's capable of solving advanced optimization issues in real time application (Mirjalili, 2015; Mirjalili and Lewis, 2016). Meta-heuristic optimization algorithms are standard in engineering applications as a result of the supply simplicity, flexibility, derivation-free mechanism, and local optima avoidance (Mirjalili et al., 2014). It solves optimization issues. Optimization suggests that to finding the most effective values for the variables of a specific downside to reduce or maximize an objective function (Saremi et al., 2017). Meta-heuristic algorithms are used in engineering and technological application (Bose and Pain, 2018). Meta-heuristic algorithms are performed random operators and familiar with stochastic optimization techniques. These 
International Journal of Mathematical, Engineering and Management Sciences

Vol. 4, No. 2, 471-488, 2019

https://dx.doi.org/10.33889/IJMEMS.2019.4.2-039

algorithms have a large number of local optima and helpful to avoid local solutions in given search space.

In this paper, HAGOA new hybrid meta-heuristic optimization algorithm is proposed for solving single-objective and multi-objective optimization issues. It will also solve problems such as slow convergence rate, avoidance local optima and balancing between exploitation and exploration phases. The rest of the paper is organized as follows: In section 2, the related work is presented. In section 3, the stochastic optimization is discussed. Section 4, presents result and efficiency evaluation using benchmark functions. In section 5, conclusion and future works is discussed.

\section{Related Work}

Meta-heuristic algorithms are divided in four categories such as evolutionary algorithms (Back, 1996), swarm intelligence algorithms (Blum and Li, 2008), Physics based algorithms and Human based algorithms. Evolutionary algorithms (EA) are optimized by natural selection. Evolutionary algorithms are heuristic-based approach to solving problems that cannot be easily solved in polynomial time, such as classically NP-Hard problems, and anything else that would take far too long to exhaustively process. EA is categorized such as Evolutionary Strategy (ES), Differential Evolution (DE), Biogeography-Based Optimization (BBO) algorithm, Evolutionary Programming (EP), and Genetic Algorithm (GA) (Fogel et al., 1966; Rechenberg, 1973; Storn and Price, 1997; Yao et al., 1999; Simon, 2008; Mirjalili and Lewis, 2016) etc. Swarm Intelligence (SI) shows a current computational and behavioral similitude for taking care of disseminated issues that initially took its motivation from the biological illustrations gave by social insects like ants, termites, honey bees, wasp. SI algorithms are categories as:

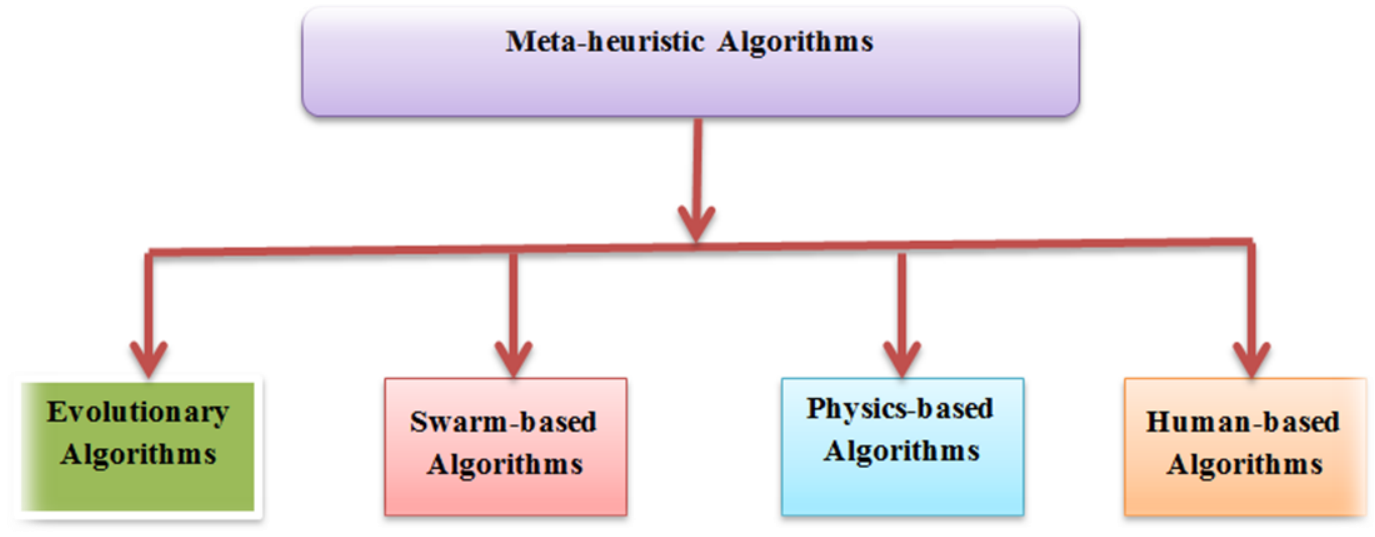

Figure 1. Meta-heuristic algorithms

Ant Colony Optimization (ACO), Honey Based Optimization (HBO), Particle Swarm Optimization (PSO) and Elephant Swarm Optimization (ESO) are most popular SI algorithms (Archie and Chiyo, 2012). ACO is performed to enhance the lifetime of WSNs with energy efficiency. Every wireless sensor node is demonstrated as a mock ant and automatic routing is the demonstrated as an ant searching. Particle swarm improvement (PSO) approach is a swarm intelligence family. PSO approach begins from the investigation of the nature of the behavior of predacious birds. The essential guideline of PSO approach is that every bird is inattentive as a 
International Journal of Mathematical, Engineering and Management Sciences

Vol. 4, No. 2, 471-488, 2019

https://dx.doi.org/10.33889/IJMEMS.2019.4.2-039

particle (Liang and Yu, 2005; Wang et al., 2010; Kaveh et at., 2014). Therefore, the increased outcome compares to the position of the particles in the search area (He and Huang, 2012).

In every cycle step, the particles are updated by following the accompanying 2 extremes: one is the best position of the neighborhood arrangement and another is that the best position of the excellent best solution. Through their learning background and therefore the commercialism of all particles information, it decides the following stage of the flight speed and direction and its steps by step advancement toward the optimal solution. Accordingly, the presentation of the PSO approach can generally enhance the WSNs execution as far as load adjusts vitality utilization and so forth. Honey Bee Optimization (HBO) approach is utilized as a part of this work to perform viable grouping of nodes based on the distance from the target point and capable to find food source based on highest fitness (Archie et al., 2006; Ari et al., 2016). Elephant Based Swarm Optimization (ESO) ways to deal with enhance WSNs lifetime. Elephants are social warmblooded creatures, and show propelled knowledge (Wilson, 2000). Elephants are frequently found to be present in a "liquid splitting combination" social condition (Krebs and Davies, 1993). Elephants portrayed by their great memory, their tendency to exist together and make due inside a cluster (Archie et al., 2006), socially detailed amid testing circumstances such as movement and when the resources are panic. Elephants identified a magnanimous conduct which empowers them to develop and is the mystery of their life span. Remembering advancement and survivability the more seasoned elephants separate or isolate from the group. Elephants by the environment are more grounded defensive of their more youthful age (Archie and Chiyo, 2012; Adams, 2013). Salp Swarm rule (SSA) is the most well-known SI approach. Salp is family of salpidae. slap chain is designed using leader and followers. It manages into two sets: leader and followers respectively. The leader is head swarm and followers are followed leader. Slap approach gave best results for single and multi-objective optimization problems (Mirjalili et al., 2017).

Some other SI algorithms are: Curved Space Optimization (CSO) (Moghaddam et al., 2012), Artificial Bee Colony (ABC) algorithm (Karaboga et al., 2007), Galaxy-based Search Algorithm (GbSA) (Shah, 2011), Cuckoo Search (CS) algorithm (Yang and Deb, 2009), Small-World Optimization Algorithm (SWOA) (Du et al., 2006), Firefly Algorithm (FA) (Yang, 2010), Ray Optimization (RO) algorithm (Kaveh and Khayataza, 2013), Bat Algorithm (BA) (Yang, April2010), Black Hole (BH) algorithm (Hatamlou, 2013), Grey Wolf Optimizer (GWO) (Mirjalili et al., 2014; Aswani et al., 2016; Kumar et al., 2017), Artificial Chemical Reaction Optimization Algorithm (ACROA) (Alatas, 2011), Dolphin Echolocation (DE) (Kaveh and Farhoudi, 2013), Central Force Optimization (CFO) (Formato, 2007), Whale Optimization Algorithm (WOA) (Mirjalili, and Lewis, 2016), Charged System Search (CSS) (Kaveh and Talatahari, 2010), Fruitfly Optimization Algorithm (FOA), Gravitational Search Algorithm (GSA) (Rashedi et al., 2009), Harmony Search (Geem et al., 2001), A powerful and efficient algorithm for numerical function optimization: artificial bee colony (ABC) algorithm (Kumar et al., 2015), Improved artificial bee colony algorithm for global optimization, Compact Optimization (Kaveh and Khayatazad, 2012; Neri et al., 2013), A global best artificial bee colony algorithm for global optimization (Gao and Liu, 2011; Abro and Mohamad, 2012), Enhanced global-best artificial bee colony optimization algorithm, Improved artificial bee colony meta-heuristic for energy-efficient clustering in wireless sensor networks (Du et al., 2006; Yang, 2010; Yang, April-2010; Kaveh and Khayatazad, 2012; Hatamlou, 2013; Aswani et al., 2016; Mirjalili et at., 2014; Mann and Singh, 2017; Kumar et al. 2017). 
International Journal of Mathematical, Engineering and Management Sciences

Vol. 4, No. 2, 471-488, 2019

https://dx.doi.org/10.33889/IJMEMS.2019.4.2-039

Another side many Physics-based algorithms are discussed in literature such as Big-Bang BigCrunch (BBBC) (Erol and Eksin, 2006), Simulated Annealing (SA) (Kirkpatrick et al., 1983) and Gravitational Local Search (GLSA) (Cerny, 1985; Webster, and Bernhard, 2003). Human behaviors based algorithm also described in literatures such as: Group Counseling Optimization (GCO) (Kashan, 2011) algorithm, Teaching Learning Based Optimization (TLBO) (Tan and Zhu, 2010), Exchange Market Algorithm (EMA), Harmony Search (HS) (Kaveh and Nasrollahi, 2014), Social-Based Algorithm (SBA), Tabu (Taboo) Search (TS) (Gandomi, 2014; Kaveh and Mahdavi, 2014), Seeker Optimization Algorithm (SOA), Group Search Optimizer (GSO) (Moosavian and Roodsari, 2014a; Sadollah et at., 2013), Soccer League Competition (SLC) algorithm, Imperialist Competitive Algorithm (ICA), Mine Blast Algorithm (MBA) (Kaveh et at., 2014), League Championship Algorithm (LCA), Colliding Bodies Optimization (CBO) (Bramer et al., 2010; Eita and Fahmy, 2014), Interior Search Algorithm (ISA) (Dai et al., 2007; Ramezani and Lotfi et al., 2013; Eita and Fahmy, 2014; Moosavian and Roodsari, 2014b), Firework Algorithm (Ghorbani et al., 2014; Mirjalili and Lewis, 2016) and Grasshopper Optimization (GOA) (Saremi et al. 2017). All types of nature-inspired algorithms are optimization of solution till the satisfactory result is not found. The optimization needs to perform on either exploration or exploitation phase. Exploration phase has a large search capability in given search space and works globally. Other side exploitation phase has a small search capability in given search space and works locally. A balancing of exploration and exploitation will give global optimum solution in given search space (He and Huang, 2012).

\section{Stochastic Optimization}

This section describes stochastic optimization. It is divided into two classes: single and multiobjective optimization. This section describes the advantage and disadvantage of single and multi-objective optimization in given search space. Single-objective optimization works with one objective and only one objective to be minimized or maximized. It is divided into two categories: equality and inequality (Mirjalili et al., 2014). It is designed as minimization problem:

$\operatorname{Min}: F(\vec{x})=\{f 1(\vec{x})\}$

Subject to: $g_{j}(\vec{x}) \geq 0, \mathrm{j}=1,2 \ldots \ldots \ldots \ldots$ ne

$h_{j}(\vec{x})=0, i=1,2, \ldots \ldots \ldots e$

$l b_{j} \leq x_{j} \leq u b_{j}, j=1,2, \ldots \ldots \ldots \ldots n$

In equation (1), f1 defines objective function. In equation (2), ne defines number of inequality constrained. In equation (3), e defines the number of equality constraints. According to equation (4) $n$ is the number of objectives and $1 b_{j}$ is the lower bound of the $j^{\text {th }}$ variable, and $u b_{j}$ indicates the upper bound of the $j^{t h}$ variable. Search space is collection of variables, the range of variables, constraints and objectives. The single objective function is only capable to draw search space in one dimension, two dimensions and three dimensions problems. But it is unable to draw more than three dimensional for search space. So that more than three dimensions be the first issue when solving the optimization problem. Other issue with single objective function is the availability of local solutions. The local solution means many other solutions give value closer to the objective value of global optimum. But the local solution is not the best solution globally into complete search space. 
International Journal of Mathematical, Engineering and Management Sciences

Vol. 4, No. 2, 471-488, 2019

https://dx.doi.org/10.33889/IJMEMS.2019.4.2-039

In exploitation phase one best solution is called global optimum in given search space. Local solutions are affected by many optimization algorithms. So during the searching local optima should be avoided and efficiently search the global optimum based on collective technique. The solution is to move globally called the exploration process. Exploration is identified as the most suitable area in the search space and avoid local solution. After completion of the exploration process, again solution move locally called exploitation process. Therefore main objective of exploitation to improve the accuracy and local solution avoidance got in exploration time.

The second side, multi- objective optimization is based on more than one objective (Pramy, 2018). All objectives should be optimized concurrently to resolve the multi-objective problem. It is derived as:

$$
\begin{aligned}
& \operatorname{Min}: F(\vec{x})=\{f 1(\vec{x}), f 2(\vec{x}) \ldots \ldots \ldots \ldots \ldots \ldots f \mathrm{o}(\vec{x})\} \\
& \text { Subject to: } g_{j}(\vec{x}) \geq 0, \mathrm{j}=1,2 \ldots \ldots \ldots \ldots \ldots \mathrm{ne} \\
& h_{j}(\vec{x})=0, j=1,2, \ldots \ldots \ldots e \\
& l b_{j} \leq x_{j} \leq u b_{j}, j=1,2, \ldots \ldots \ldots \ldots n
\end{aligned}
$$

Where, the equation (5), fo defines number of objectives. Equation (6), ne defines number of inequality constrained. In equation (7), e defines number of equality constraints. In the last equation (8), $n$ defines number of variables and $1 b_{j}$ defines the lower bound of the $j^{\text {th }}$ variable, and $\mathrm{ub}_{\mathrm{j}}$ indicates the upper bound of the $j^{\text {th }}$ variable. The multi-objective problem should be resolved based on relational operators. Relational operators make comparison between two solutions generated by a multi-objective function called Pareto optimal dominance (dominating solution) and without holding of two solutions called non dominated solution. Therefore, Pareto optimal plays more significant role in multi-objective optimization. It is identified as the best optimal solution among the multiple solutions. The pareto optimal set is optimized multiple solutions and projected in objective space called optimal front. Proper balancing between exploitation and exploration phases, slow convergence and avoid local solution are common issues between single objective and multi-objective. Other optimization algorithms have applied to solve single and multiple objective problems like Multi-Objective Evolutionary Algorithm based on Decomposition (MOEA/D), ABC, Non-dominated Sorting Genetic Algorithm version 2 (NSGAII) and DE-based methods, Pareto-frontier Differential Evolution (PDE), PSO. Based on the various benefits of proposed algorithms in literature and tested by the No-Free-Lunch (NFL) that all nature inspired algorithms are unable to resolve all optimization issues. That's why always the chance to bring a new algorithm. In this paper, HAGOA hybrid meta-heuristic optimization algorithm is proposed for solving single-objective and multi-objective optimization issues. It will also solve problems such as slow convergence rate, avoidance local optima and balancing between exploitation and exploration phases.

\section{Result and Efficiency Evaluation Using Benchmark Functions}

The proposed Hybrid Artificial Grasshopper Optimization (HAGOA) meta-heuristic algorithm is compared with Artificial Grasshopper Optimization (AGOA) (Saremi et al., 2017), Hybrid Artificial Bee Colony with Salp (HABCS), Modify Artificial Bee Colony (MABC) (Gao et al., 2012) and Modify Particle Swarm Optimization (MPSO) (He and Huang, 2012) to count efficiency evaluation. The numerical efficiency of HAGOA algorithm is tested by nineteen 
International Journal of Mathematical, Engineering and Management Sciences

Vol. 4, No. 2, 471-488, 2019

https://dx.doi.org/10.33889/IJMEMS.2019.4.2-039

benchmark functions. These nineteen benchmark functions are used in optimization literature (Dai et al., 2007; Karaboga and Basturk, 2007; Gao et al., 2013; Saremi et al., 2017). The benchmark test functions are divided into two categories: Unimodal and multimodal. Unimodal functions (F1-F8) are defined in Table 1 and multimodal functions (F9-F19) are defined in Table 2. For all the algorithms, a population size varies from 10 to 100 .

Table 1. Unimodal benchmark functions

\begin{tabular}{|c|c|c|c|}
\hline Acronym & Function & Dim & Search Range \\
\hline $\mathrm{F} 1$ & $f(y)=$ & 05 & {$[-100,100]$} \\
\hline $\mathrm{F} 2$ & $f(y)=\sum_{j=1}^{n} y_{j}^{2}$ & 05 & {$[-100,100]$} \\
\hline F3 & $f(y)=\sum_{j=1}^{n} j y_{j}^{4}+\operatorname{random}[0,1)$ & 05 & {$[-100,100]$} \\
\hline $\mathrm{F} 4$ & $\begin{array}{l}f(y)=100\left(y_{1}^{2}-y_{2}\right)^{2}+\left(y_{1}-1\right)^{2} \\
+\left(y_{3}-1\right)^{2}+90\left(y_{3}^{2}-y_{4}\right)^{2} \\
+10.1\left(\left(y_{2}-1\right)^{2}+\left(y_{4}-1\right)^{2}\right) \\
+19.8\left(y_{2}-1\right)\left(y_{4}-1\right)\end{array}$ & 05 & {$[-100,100]$} \\
\hline F5 & $f(y)=\sum_{j=1}^{n}\left[100\left(y_{j+1}-y_{j}^{2}\right)^{2}+\left(y_{j}-1\right)^{2}\right]$ & 05 & {$[-100,100]$} \\
\hline F6 & $\begin{array}{l}f(y)=\sum_{(j=1)}^{(n / k)}\left(y_{(4 j-3)}+10 y_{(4 j-2)}\right)^{2} \\
+5\left(y_{(4 j-1)}+y_{4} j\right)^{2}+\left(y_{(4 j-2)}+y_{(4 j-1)}\right)^{4} \\
+10\left(y_{(4 j-3)}+y_{4} j\right)^{4}\end{array}$ & 05 & {$[-100,100]$} \\
\hline F7 & $f(x)=-\left(x_{1}-1\right)^{2}+\sum_{i=0}^{n} i\left(2 x_{i}^{2}-x_{i}-1\right)^{2}$ & 05 & {$[-100,100]$} \\
\hline F8 & $\begin{array}{l}f(x)=-\cos \left(x_{1}\right) \cos \left(x_{2}\right) \\
\exp \left(-\left(x_{1}-\pi\right)^{2}-\left(x_{2}-\pi\right)^{2}\right)\end{array}$ & 05 & {$[-100,100]$} \\
\hline
\end{tabular}


International Journal of Mathematical, Engineering and Management Sciences

Vol. 4, No. 2, 471-488, 2019

https://dx.doi.org/10.33889/IJMEMS.2019.4.2-039

Table 2. Multimodal benchmark functions

\begin{tabular}{|c|c|c|c|}
\hline Acronym & Function & Dim & Search Range \\
\hline F9 & $f(x)=\sum_{i=1} x_{i}^{2}-10 \cos \left(2 \pi x_{i}\right)+10$ & 05 & {$[-100,100]$} \\
\hline F10 & $f(x)=\sum_{i=1}^{n}$ & 05 & {$[-100,100]$} \\
\hline F11 & $f(x)=-\sum_{i=1} \sin \left(x_{i}\right)\left(\sin \left(i x_{i}^{2} / \pi\right)\right)^{2 m}$ & 06 & {$[-100,100]$} \\
\hline F12 & $f(x)=\left[\frac{1}{500}+\sum_{j=1}^{25} \frac{1}{j+\sum_{i=1}^{2}\left(x_{i}-a_{i j}\right)^{6}}\right]-1$ & 02 & {$[-100,100]$} \\
\hline F13 & $f(x)=-\sum_{i=1}^{5}[(x$ & 06 & {$[-100,100]$} \\
\hline F14 & $f(x)=\sum_{k=1}^{n} \sum_{i=1}^{n}$ & 02 & {$[-100,100]$} \\
\hline F15 & $f(x)=\sum_{i=1}^{p}\left(A_{i}-B_{i}\right)^{2}$ & 05 & {$[-100,100]$} \\
\hline F16 & $\begin{array}{l}f(x)=-\sum_{i=1}^{m} c_{i}\left(\exp \left(-1 / \sum_{(j=1)}^{n}\left(x_{j}-a_{i} j\right)^{2}\right.\right. \\
\left.\left.\cos \left(\pi \sum_{(j=1)}^{n}\left(x_{j}-a_{i} j\right)^{2}\right)\right)\right)\end{array}$ & 05 & {$[-100,100]$} \\
\hline F17 & $f(x)=0.5+\frac{\sin ^{2}\left(\sqrt{x_{1}^{2}+x_{2}^{2}}\right)-0.5}{\left(1+0.0001\left(\sqrt{x_{1}^{2}+x_{2}^{2}}\right)\right)^{2}}$ & 05 & {$[-100,100]$} \\
\hline F18 & $f(x)=\frac{1}{4000} \sum_{i=1}^{n} x_{i}^{2}-\prod_{i=1}^{n} \cos \frac{x_{i}}{\sqrt{i}}+1$ & 05 & {$[-100,100]$} \\
\hline F19 & $f(x)=\sum_{i=1}^{11}\left(a_{i}-\frac{x_{1}\left(b_{i}^{2}+b_{i} x_{2}\right)}{b_{i}^{2}+b_{i} x_{3}+x_{4}}\right)^{2}$ & 05 & {$[-100,100]$} \\
\hline
\end{tabular}

\subsection{Efficiency Evaluation of the Algorithm Using Unimodal Benchmark Functions}

Uni-modal has single optimum solution and it is analyzed exploitation space, local search space and convergence rate of the proposed HAGOA and existing algorithms. Functions F1 to F8 in above defined in Table 1. The different iterations are running 40 times for all algorithms and start with different population's randomly generated result based on average cost (mean) function and standard deviation. HAGOA is compared with AGOA, HABCS, MABC and MPOS algorithms using benchmark functions. Figure 2 to Figure 9 represent unimodal test functions. HAGOA is more efficient than AGOA, HABC, MABC, and MPSO on the popular of test cases. It is also proved that suitable for high exploitation. 
International Journal of Mathematical, Engineering and Management Sciences

Vol. 4, No. 2, 471-488, 2019

https://dx.doi.org/10.33889/IJMEMS.2019.4.2-039
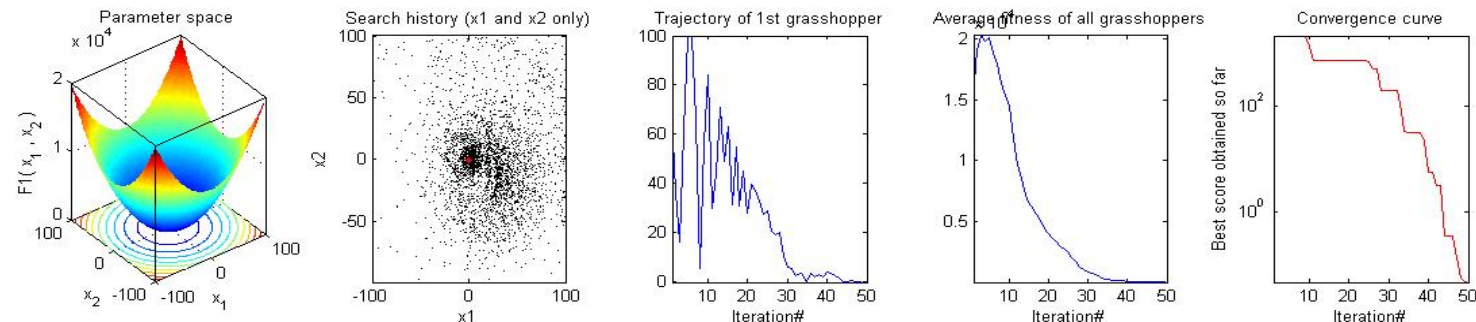

Figure 2. HAGOA search behavior on unimodal function (F1)
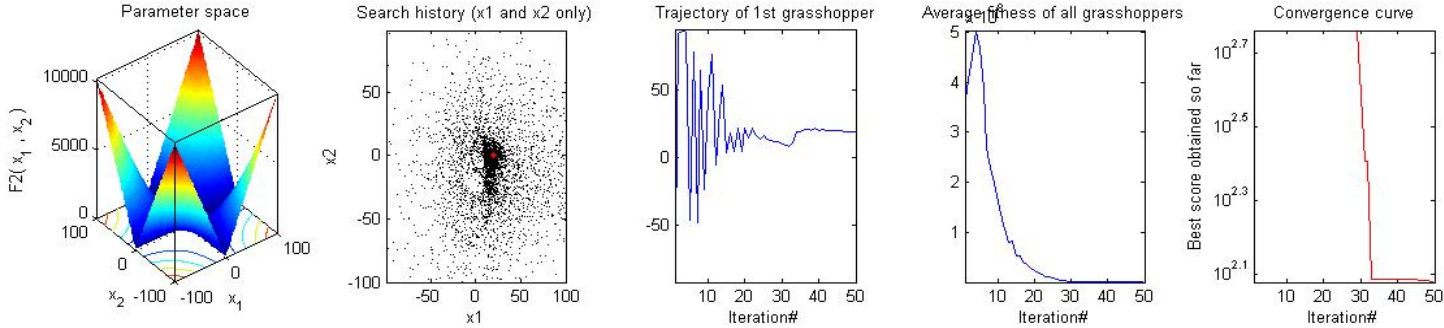

Figure 3. HAGOA search behavior on unimodal function (F2)
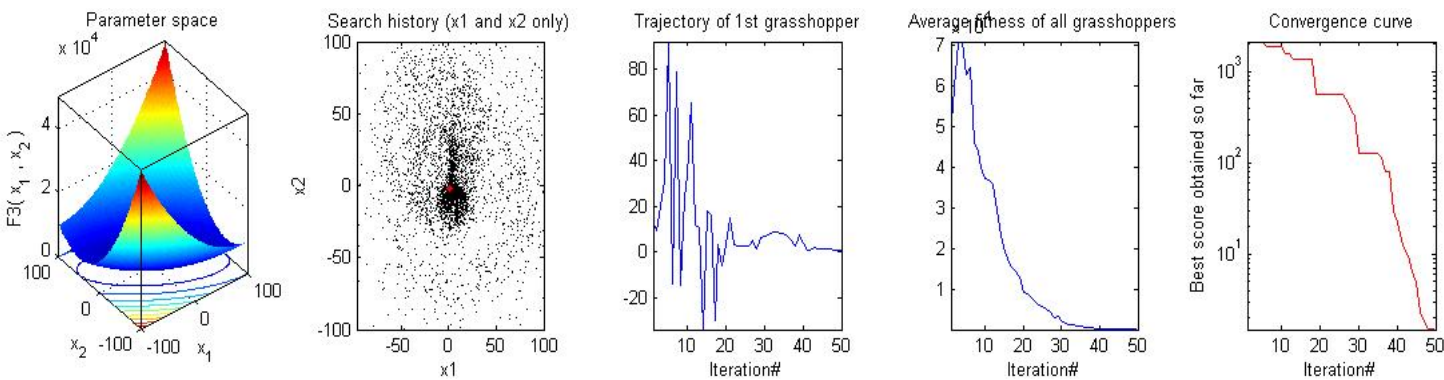

Figure 4. HAGOA search behavior on unimodal function (F3)
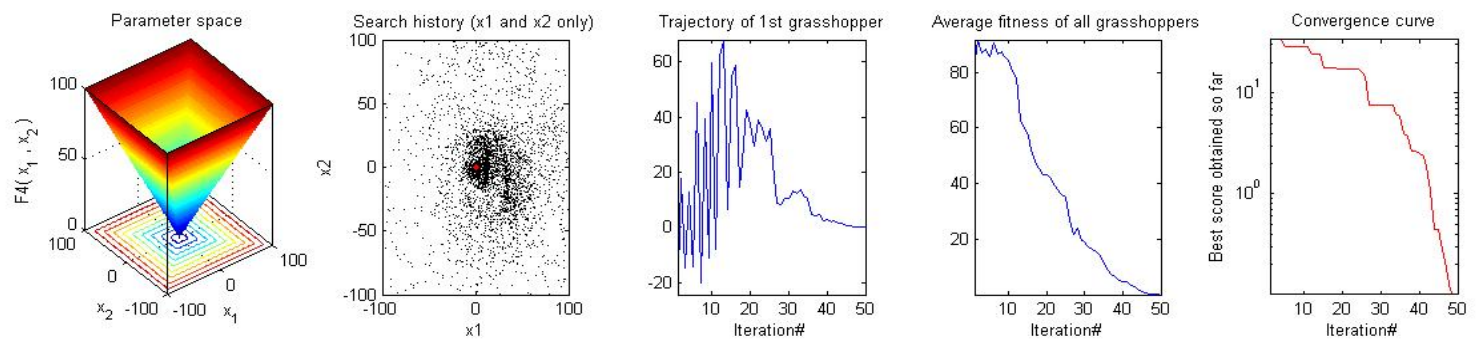

Figure 5. HAGOA search behavior on unimodal function $(\mathrm{F} 4)$ 
International Journal of Mathematical, Engineering and Management Sciences

Vol. 4, No. 2, 471-488, 2019

https://dx.doi.org/10.33889/IJMEMS.2019.4.2-039
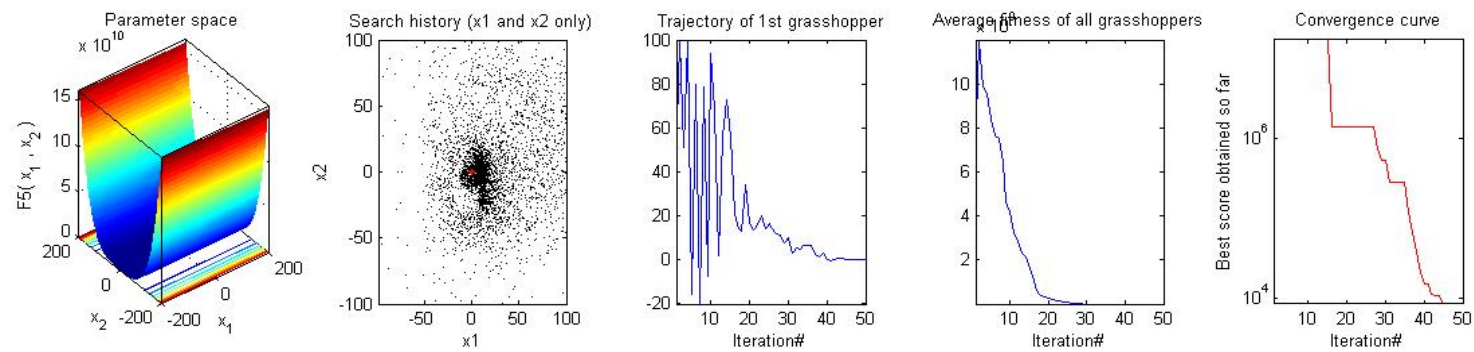

Figure 6. HAGOA search behavior on unimodal function (F5)
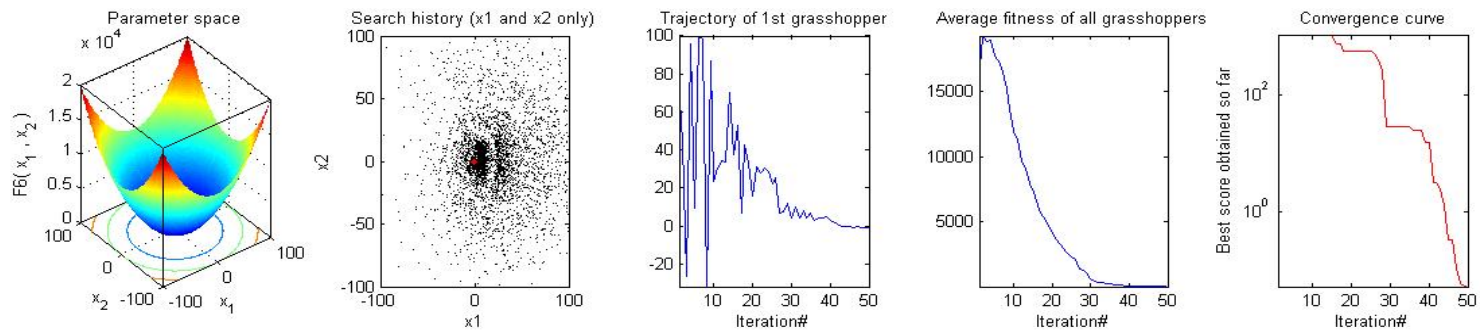

Figure 7. HAGOA search behavior on unimodal function (F6)
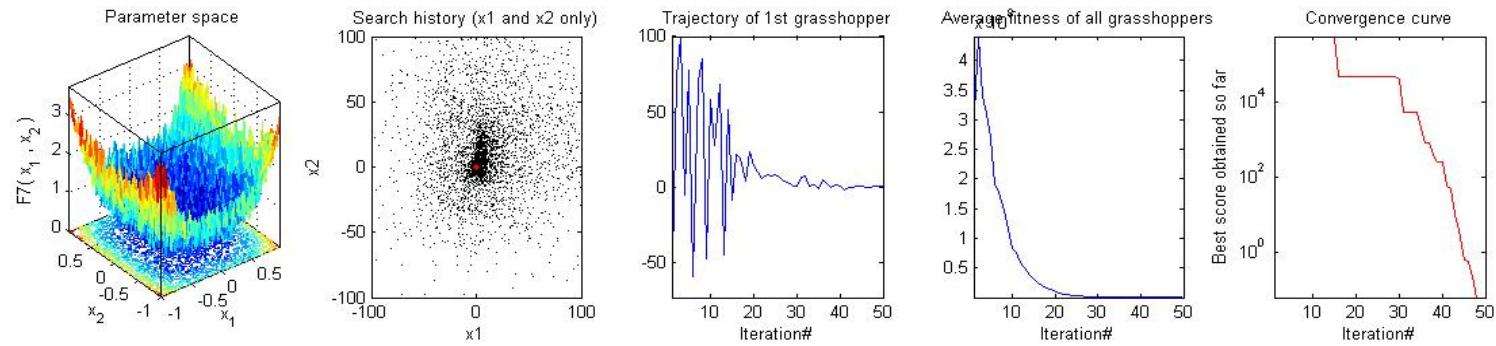

Figure 8. HAGOA search behavior on unimodal function (F7)
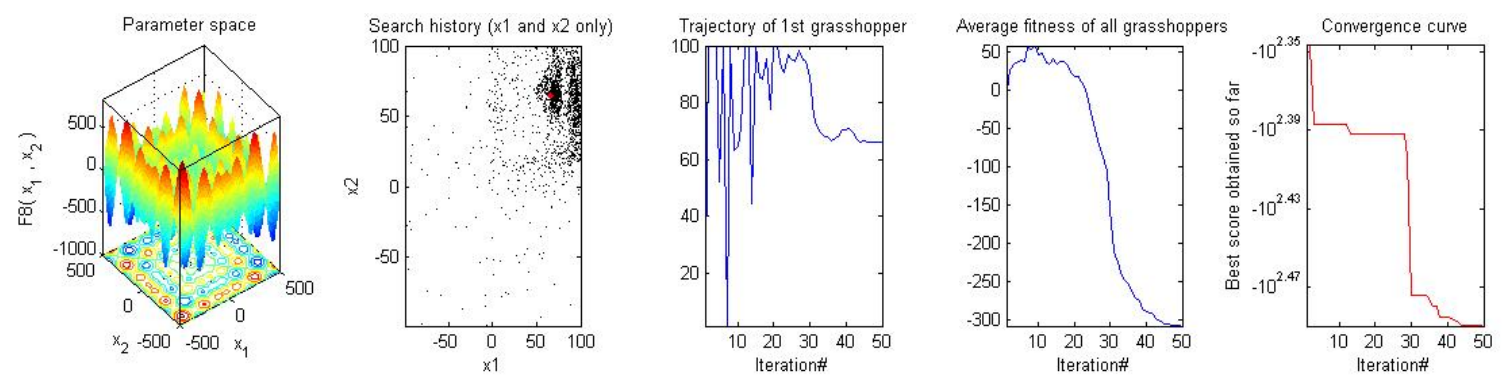

Figure 9. HAGOA search behavior on unimodal function (F8) 
International Journal of Mathematical, Engineering and Management Sciences

Vol. 4, No. 2, 471-488, 2019

https://dx.doi.org/10.33889/IJMEMS.2019.4.2-039

Table 3. Performance evaluation on unimodal functions

\begin{tabular}{|c|c|c|c|c|c|c|}
\hline \multicolumn{2}{|c|}{ Function } & MPSO & MABC & HABCS & AGOA & HAGOA \\
\hline \multirow{2}{*}{ F1 } & Avg. & $4.981 \mathrm{E}-07$ & $4.234 \mathrm{E}-9$ & $4.198 \mathrm{E}-10$ & $5.187 \mathrm{E}-12$ & $2.798 \mathrm{E}-17$ \\
\cline { 2 - 7 } & Std. & $\pm 0.010 \mathrm{E}+00$ & $\pm 0.009 \mathrm{E}+00$ & $\pm 0.003 \mathrm{E}+00$ & $\pm 0.044 \mathrm{E}+00$ & $\pm 0.110 \mathrm{E}+00$ \\
\hline \multirow{2}{*}{ F2 } & Avg. & $0.010 \mathrm{E}+00$ & $1.653 \mathrm{E}-09$ & $1.010 \mathrm{E}-12$ & $1.781 \mathrm{E}-09$ & $0.010 \mathrm{E}-12$ \\
\cline { 2 - 7 } & Std. & $\pm 0.0004 \mathrm{E}+00$ & $\pm 2.101 \mathrm{E}+00$ & $\pm 1.008 \mathrm{E}+00$ & $\pm 3.171 \mathrm{E}+00$ & $\pm 0.004 \mathrm{E}+00$ \\
\hline \multirow{2}{*}{ F3 } & Avg. & $1.157 \mathrm{E}-03$ & $0.800 \mathrm{E}-04$ & $0.698 \mathrm{E}-08$ & $0.907 \mathrm{E}-04$ & $0.757 \mathrm{E}-08$ \\
\cline { 2 - 7 } & Std. & $\pm 1.760 \mathrm{E}-04$ & $\pm 0.911 \mathrm{E}-02$ & $\pm 0.780 \mathrm{E}-03$ & $\pm 8.911 \mathrm{E}-02$ & $\pm 6.780 \mathrm{E}-03$ \\
\hline \multirow{2}{*}{ F4 } & Avg. & $0.008 \mathrm{E}+00$ & $0.144 \mathrm{E}-04$ & $0.053 \mathrm{E}-07$ & $0.944 \mathrm{E}-03$ & $0.078 \mathrm{E}-07$ \\
\cline { 2 - 7 } & Std. & $\pm 0.010 \mathrm{E}+00$ & $\pm 0.266 \mathrm{E}-00$ & $\pm 0.123 \mathrm{E}+00$ & $\pm 0.356 \mathrm{E}-00$ & $\pm 0.011 \mathrm{E}+00$ \\
\hline \multirow{2}{*}{ F5 } & Avg. & $1.100 \mathrm{E}-06$ & $1.654 \mathrm{E}-08$ & $0.111 \mathrm{E}-13$ & $1.870 \mathrm{E}-09$ & $0.100 \mathrm{E}-12$ \\
\cline { 2 - 7 } & Std. & $\pm 0.040 \mathrm{E}-06$ & $\pm 1.660 \mathrm{E}-08$ & $\pm 0.104 \mathrm{E}-08$ & $\pm 1.660 \mathrm{E}-08$ & $\pm 0.140 \mathrm{E}-08$ \\
\hline \multirow{2}{*}{ F6 } & Avg. & $5.748 \mathrm{E}-01$ & $2.189 \mathrm{E}-05$ & $2.148 \mathrm{E}-06$ & $1.789 \mathrm{E}-02$ & $3.748 \mathrm{E}-07$ \\
\cline { 2 - 7 } & Std. & $\pm 3.037 \mathrm{E}+01$ & $\pm 2.538 \mathrm{E}+00$ & $\pm 2.987 \mathrm{E}+00$ & $\pm 4.838 \mathrm{E}+00$ & $\pm 2.137 \mathrm{E}+00$ \\
\hline \multirow{2}{*}{ F7 } & Avg. & $6.667 \mathrm{E}-03$ & $1.127 \mathrm{E}-05$ & $1.337 \mathrm{E}-07$ & $1.237 \mathrm{E}-03$ & $1.667 \mathrm{E}-08$ \\
\cline { 2 - 7 } & Std. & $\pm 0.000 \mathrm{E}+00$ & $\pm 0.100 \mathrm{E}+00$ & $\pm 0.097 \mathrm{E}+00$ & $\pm 0.100 \mathrm{E}+00$ & $\pm 0.010 \mathrm{E}+00$ \\
\hline \multirow{2}{*}{ F8 } & Avg. & $0.900 \mathrm{E}+00$ & $1.817 \mathrm{E}-07$ & $0.700 \mathrm{E}-13$ & $-1.180 \mathrm{E}-07$ & $-0.900 \mathrm{E}-12$ \\
\cline { 2 - 7 } & Std. & $\pm 0.080 \mathrm{E}+00$ & $\pm 0.60 \mathrm{E}+00$ & $\pm 0.040 \mathrm{E}+02$ & $\pm 0.100 \mathrm{E}+00$ & $\pm 0.080 \mathrm{E}+02$ \\
\hline
\end{tabular}

\subsection{Efficiency Evaluation of the Algorithm Using Multi-modal Benchmarks Functions}

The HAGOA algorithm is running 40 times start with different populations and randomly generated result based on average cost (mean) function and standard deviation. HAGOA is compared with AGOA, HABCS, MABC, and MPSO algorithms using benchmark multi-modal functions. Efficiency analyzed of algorithms on unites functions according to Table 3. Figure 10 to Figure 20 represent the multi-modal test functions. It is proved that HAGOA is more efficient than AGOA, HABCS, MABC, and MPSO on the popular of test cases. It is also proved that suitable for high exploration. High exploration helps to select the most promising region in search space. Table 4 is proved high convergence rates in search space. It is fulfilled local optimum avoidance condition and able to select global optimum one.
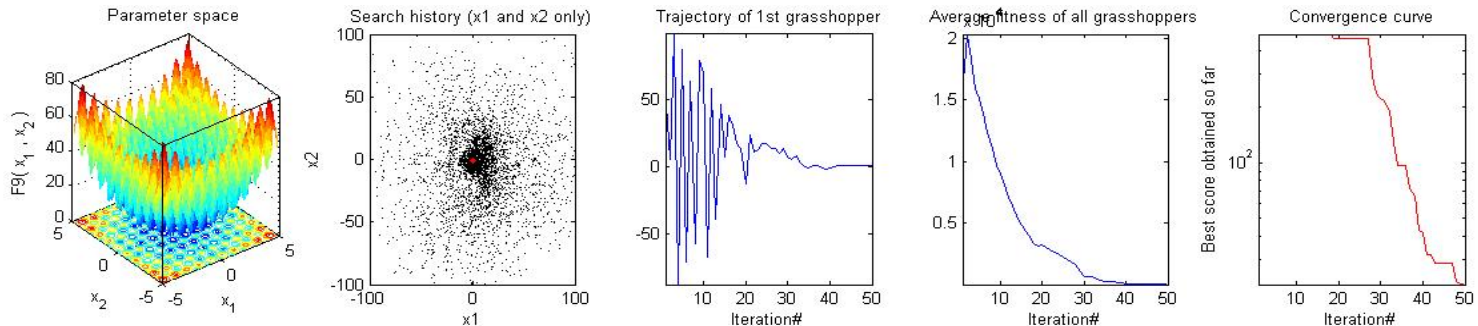

Figure 10. HAGOA behavior on multimodal function (F9) 
International Journal of Mathematical, Engineering and Management Sciences

Vol. 4, No. 2, 471-488, 2019

https://dx.doi.org/10.33889/IJMEMS.2019.4.2-039
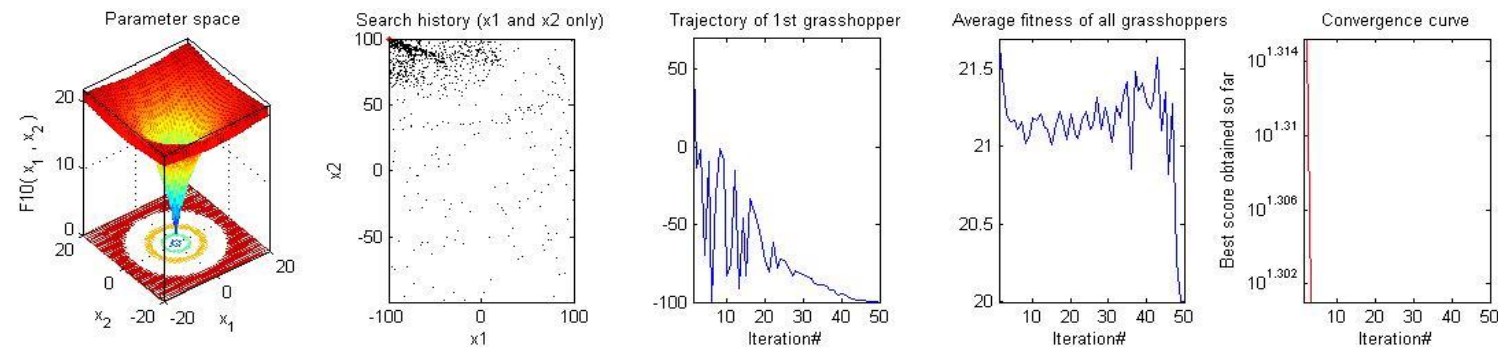

Figure 11. HAGOA behavior on multimodal function (F10)
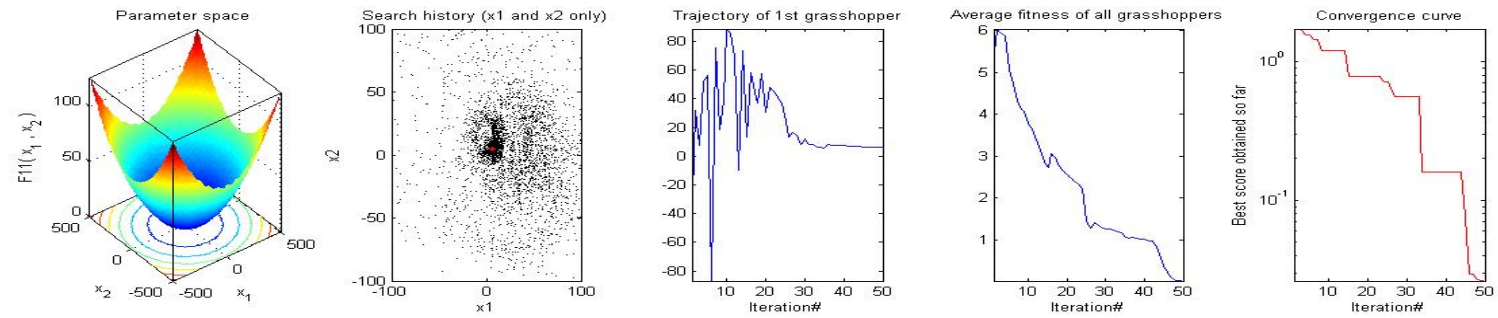

Figure 12. HAGOA behavior on multimodal function (F11)
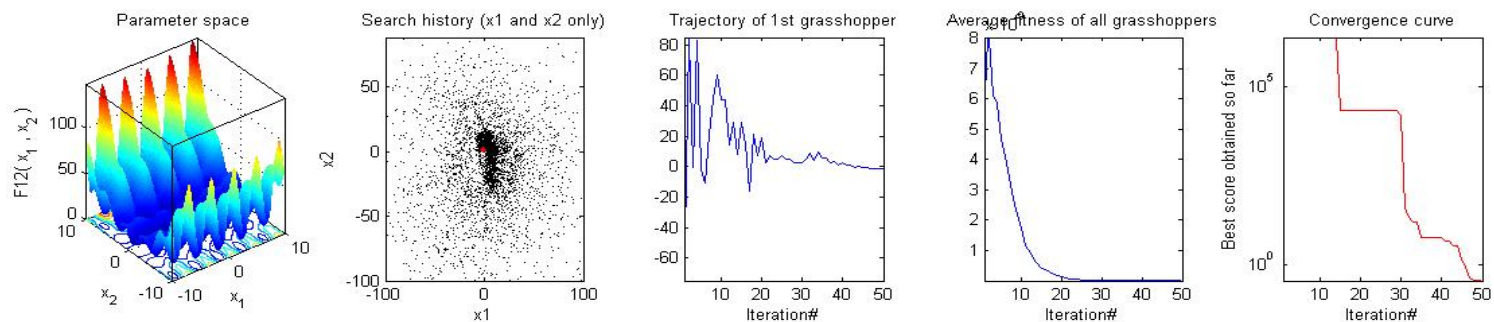

Figure 13. HAGOA behavior on multimodal function (F12)
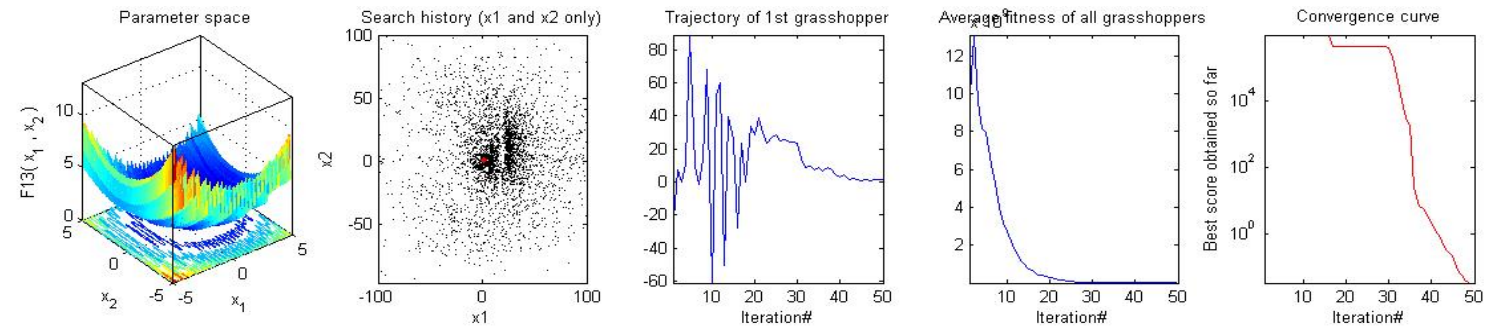

Figure 14. HAGOA behavior on multimodal function (F13) 
International Journal of Mathematical, Engineering and Management Sciences

Vol. 4, No. 2, 471-488, 2019

https://dx.doi.org/10.33889/IJMEMS.2019.4.2-039
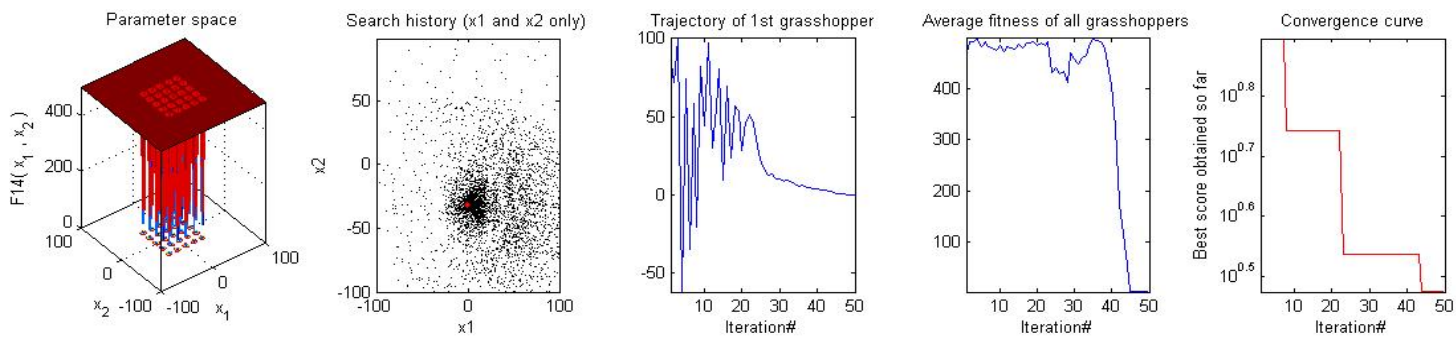

Figure 15. HAGOA behavior on multimodal function (F14)
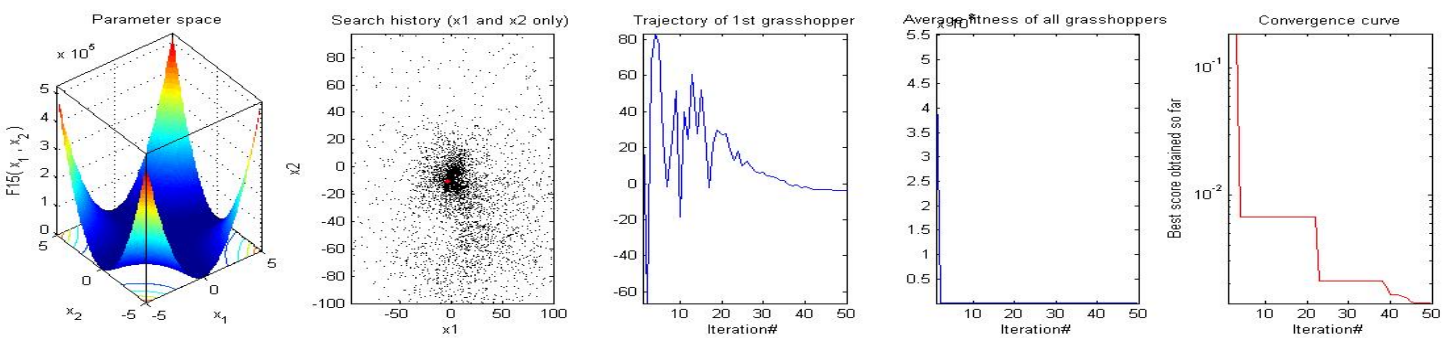

Figure 16. HAGOA behavior on multimodal function (F15)
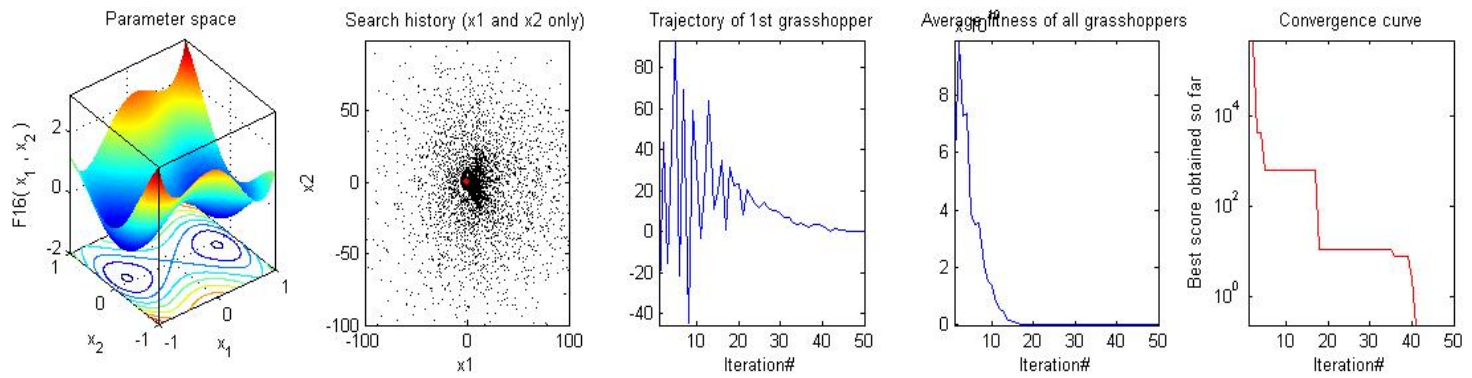

Figure 17. HAGOA behavior on multimodal function (F16)
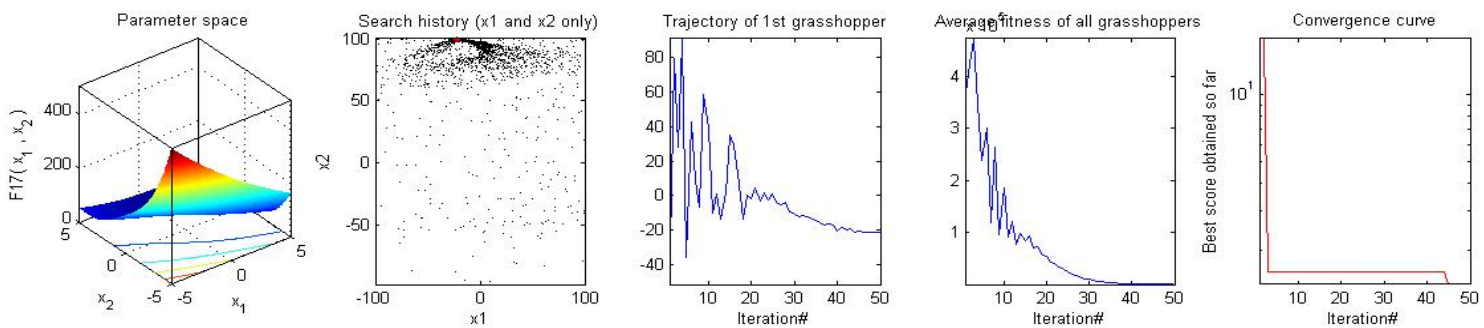

Figure 18. HAGOA behavior on multimodal function (F17) 
International Journal of Mathematical, Engineering and Management Sciences

Vol. 4, No. 2, 471-488, 2019

https://dx.doi.org/10.33889/IJMEMS.2019.4.2-039
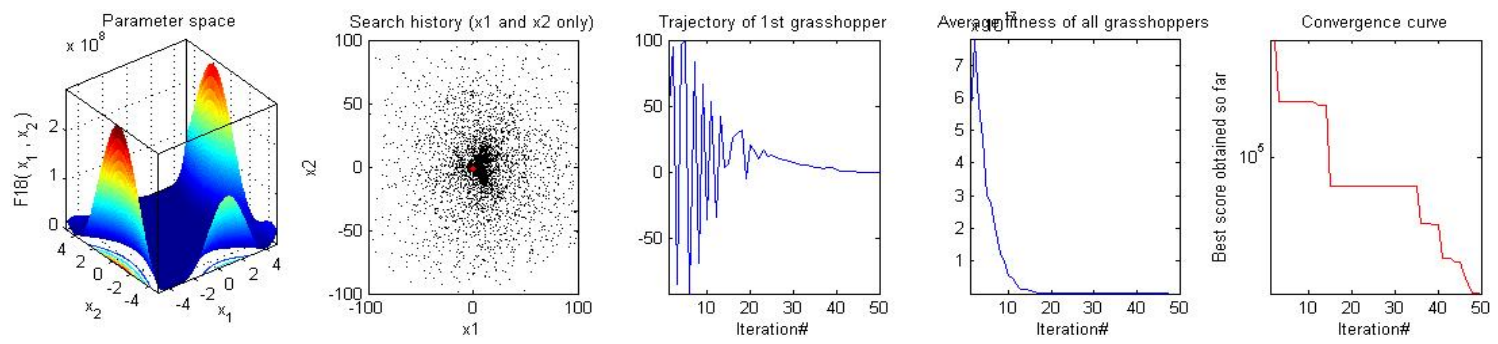

Figure 19. HAGOA behavior on multimodal function (F18)
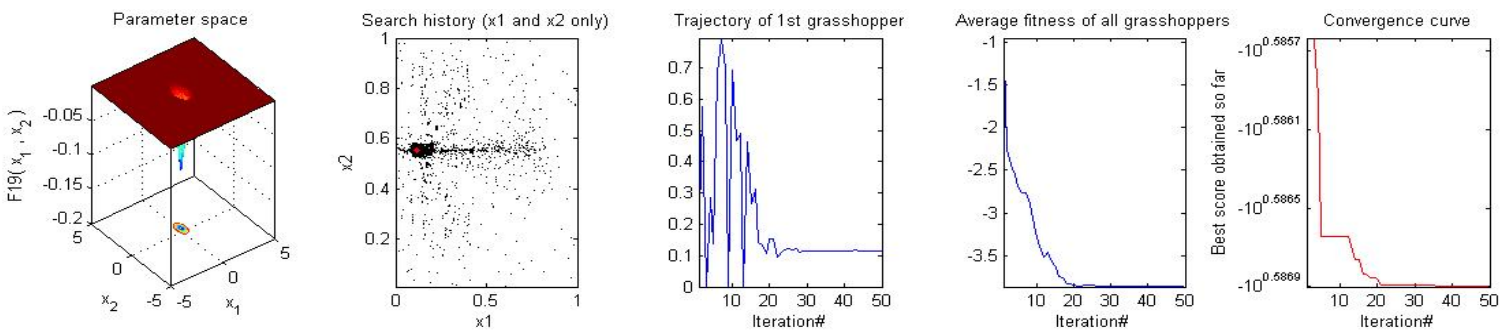

Figure 20. HAGOA behavior on multimodal function (F19)

Table 4. Performance evaluation on multimodal functions

\begin{tabular}{|c|c|c|c|c|c|c|}
\hline \multicolumn{2}{|c|}{ Function } & MPSO & MABC & HABCS & AGOA & HAGOA \\
\hline \multirow{2}{*}{ F9 } & Avg. & $-6.909 \mathrm{E}-7$ & $-0.566 \mathrm{E}-07$ & $-0.539 \mathrm{E}-12$ & $-1.0266 \mathrm{E}-8$ & $-1.239 \mathrm{E}-12$ \\
\cline { 2 - 7 } & Std. & $\pm 6.790 \mathrm{E}+02$ & $\pm 2.876 \mathrm{E}-02$ & $\pm 1.895 \mathrm{E}-02$ & $\pm 2.208 \mathrm{E}-02$ & $\pm 1.875 \mathrm{E}-02$ \\
\hline \multirow{2}{*}{ F10 } & Avg. & $1.681 \mathrm{E}-01$ & $0.965 \mathrm{E}-05$ & $1.263 \mathrm{E}-8$ & $0.225 \mathrm{E}-05$ & $1.373 \mathrm{E}-09$ \\
\cline { 2 - 7 } & Std. & $\pm 7.412 \mathrm{E}+00$ & $\pm 1.538 \mathrm{E}-01$ & $\pm 2.114 \mathrm{E}-03$ & $\pm 1.538 \mathrm{E}-01$ & $\pm 2.564 \mathrm{E}-03$ \\
\hline \multirow{2}{*}{ F11 } & Avg. & $9.980 \mathrm{E}-03$ & $2.011 \mathrm{E}-05$ & $4.291 \mathrm{E}-09$ & $1.034-03$ & $6.993 \mathrm{E}-10$ \\
\cline { 2 - 7 } & Std. & $\pm 0.030 \mathrm{E}+00$ & $\pm 0.440 \mathrm{E}-01$ & $\pm 0.321 \mathrm{E}-02$ & $\pm 0.540 \mathrm{E}-01$ & $\pm 0.110 \mathrm{E}-02$ \\
\hline \multirow{2}{*}{ F12 } & Avg. & $-1.087 \mathrm{E}-01$ & $-0.215 \mathrm{E}-04$ & $-0.859 \mathrm{E}-09$ & $-0.315 \mathrm{E}-03$ & $-1.652 \mathrm{E}-09$ \\
\cline { 2 - 7 } & Std. & $\pm 5.878 \mathrm{E}+00$ & $\pm 0.409 \mathrm{E}-03$ & $\pm 2.543 \mathrm{E}-04$ & $\pm 0.309 \mathrm{E}-02$ & $\pm 2.121 \mathrm{E}-03$ \\
\hline \multirow{2}{*}{ F13 } & Avg. & $3.605 \mathrm{E}-03$ & $2.586 \mathrm{E}-04$ & $0.543 \mathrm{E}-08$ & $3.786 \mathrm{E}-06$ & $0.419 \mathrm{E}-09$ \\
\cline { 2 - 7 } & Std. & $\pm 4.893 \mathrm{E}-02$ & $\pm 2.137 \mathrm{E}-02$ & $\pm 0.478 \mathrm{E}-01$ & $\pm 2.137 \mathrm{E}-02$ & $\pm 0.478 \mathrm{E}-01$ \\
\hline \multirow{2}{*}{ F14 } & Avg. & $0.070 \mathrm{E}-05$ & $0.123 \mathrm{E}-09$ & $0.101 \mathrm{E}-12$ & $0.070 \mathrm{E}-12$ & $0.100 \mathrm{E}-29$ \\
\cline { 2 - 7 } & Std. & $\pm 0.600 \mathrm{E}-08$ & $\pm 0.600 \mathrm{E}-01$ & $\pm 0.100 \mathrm{E}-02$ & $\pm 0.600 \mathrm{E}-01$ & $\pm 0.100 \mathrm{E}-02$ \\
\hline \multirow{2}{*}{ F15 } & Avg. & $0.100 \mathrm{E}-08$ & $-1.721 \mathrm{E}-04$ & $-1.594 \mathrm{E}-09$ & $-1.423 \mathrm{E}-04$ & $-2.694 \mathrm{E}-07$ \\
\cline { 2 - 7 } & Std. & $\pm 0.010 \mathrm{E}+00$ & $\pm 1.812 \mathrm{E}-02$ & $\pm 1.101 \mathrm{E}-03$ & $\pm 1.812 \mathrm{E}-02$ & $\pm 1.101 \mathrm{E}-03$ \\
\hline \multirow{2}{*}{ F16 } & Avg. & $5.760 \mathrm{E}-03$ & $0.876 \mathrm{E}-09$ & $0.131 \mathrm{E}-13$ & $1.189 \mathrm{E}-09$ & $1.139 \mathrm{E}-13$ \\
\cline { 2 - 7 } & Std. & $\pm 1.000 \mathrm{E}-02$ & $\pm 3.785 \mathrm{E}-03$ & $\pm 3.834 \mathrm{E}-03$ & $\pm 3.785 \mathrm{E}-03$ & $\pm 3.834 \mathrm{E}-03$ \\
\hline \multirow{2}{*}{ F17 } & Avg. & $9.877 \mathrm{E}-05$ & $0.166 \mathrm{E}-05$ & $0.664 \mathrm{E}-10$ & $0.183 \mathrm{E}-05$ & $0.794 \mathrm{E}-09$ \\
\cline { 2 - 7 } & Std. & $\pm 1.158 \mathrm{E}-02$ & $\pm 2.291 \mathrm{E}-01$ & $\pm 1.161 \mathrm{E}-01$ & $\pm 2.291 \mathrm{E}-01$ & $\pm 1.161 \mathrm{E}-01$ \\
\hline \multirow{2}{*}{ F18 } & Avg. & $3.976 \mathrm{E}-04$ & $1.000 \mathrm{E}-06$ & $1.007 \mathrm{E}-09$ & $1.187 \mathrm{E}-05$ & $1.927 \mathrm{E}-11$ \\
\cline { 2 - 7 } & Std. & $\pm 1.860 \mathrm{E}-04$ & $\pm 6.181 \mathrm{E}-04$ & $\pm 0.181 \mathrm{E}-06$ & $\pm 8.781 \mathrm{E}-05$ & $\pm 0.981 \mathrm{E}-05$ \\
\hline \multirow{2}{*}{ F19 } & Avg. & $1.457 \mathrm{E}-02$ & $2.303 \mathrm{E}-02$ & $1.127 \mathrm{E}+03$ & $4.303 \mathrm{E}-03$ & $1.457 \mathrm{E}+03$ \\
\cline { 2 - 7 } & Std. & $\pm 1.269 \mathrm{E}-02$ & $\pm 9.469 \mathrm{E}-03$ & $\pm 1.269 \mathrm{E}+03$ & $\pm 9.469 \mathrm{E}-03$ & $\pm 1.269 \mathrm{E}+03$ \\
\hline
\end{tabular}


International Journal of Mathematical, Engineering and Management Sciences

Vol. 4, No. 2, 471-488, 2019

https://dx.doi.org/10.33889/IJMEMS.2019.4.2-039

\section{Conclusion and Future Work}

This paper is proposed Hybrid Artificial Grasshopper Optimization (HAGOA) meta-heuristics algorithm. It is merged features of AGOA and Salp swarm intelligence. It is improved exploitation, exploration, convergence rates and balance in exploitation and exploration phased in given search space. The efficiency of HAGOA algorithm is evaluated using unimodal (F1-F8) and multimodal (F9-F19) benchmark functions. HAGOA is proved that more suitable for high exploitation and it is capable to balance between exploitation and exploration phases in given search space. It is also improved convergence rate in given search space. In this paper, high exploitation helps to select optimal search space and high exploration helps to select the most promising region in search space. It is satisfied local avoidance condition and it is also capable to select global optimal in given search space. In this paper, HAGOA meta-heuristics algorithm has proved efficiency using unimodal and multimodal benchmark function compared with variants of swarm intelligence algorithms. In future work, HAGOA meta-heuristic algorithm will be applied in wireless sensor networks to increase lifetime and improve energy efficiency.

\section{Conflict of Interest}

The authors confirm that this article contents have no conflict of interest.

\section{Acknowledgement}

The authors acknowledge I. K. Gujral Punjab Technical University, Kapurthala, India for providing research facilities.

\section{References}

Abro, A. G., \& Mohamad-Saleh, J. (2012, November). Enhanced global-best artificial bee colony optimization algorithm. In Computer Modeling and Simulation (EMS), 2012 Sixth UKSim/AMSS European Symposium on (pp. 95-100). IEEE.

Adams, R. (2013). Social behavior and communication in elephants- it's true! elephants don't forget! Available at: http://www.wildlifepictures-online.com/ elephant-communication.html.

Alatas, B. (2011). ACROA: Artificial chemical reaction optimization algorithm for global optimization. Expert Systems with Applications, 38(10), 13170-13180.

Archie, E. A., \& Chiyo, P. I. (2012). Elephant behavior and conservation: social relationships, the effects of poaching, and genetic tools for management. Molecular Ecology, 21(3), 765-778.

Archie, E. A., Moss, C. J., \& Alberts, S. C. (2006). The ties that bind: genetic relatedness predicts the fission and fusion of social groups in wild African elephants. Proceedings of the Royal Society of London B: Biological Sciences, 273(1586), 513-522.

Ari, A., Yenke, B. O. , Labraoui, N., Damakoa, I., \& Gueroui, A. (2016). A power efficient cluster based routing algorithm for wireless sensor networks: Honey bees swarm intelligence based approach. Elsevier, Journal of Network and Computer Applications, 69, 77-97. 
International Journal of Mathematical, Engineering and Management Sciences

Vol. 4, No. 2, 471-488, 2019

https://dx.doi.org/10.33889/IJMEMS.2019.4.2-039

Aswani, R., Ghrera, S. P., \& Chandra, S. (2016). A novel approach to outlier detection using modified grey wolf optimization and k-nearest neighbors algorithm. Indian Journal of Science and Technology, 9(44), 1-8.

Back, T. (1996). Evolutionary algorithms in theory and practice, evolution strategies, evolutionary programming, genetic algorithms. Oxford University Press.

Blum, C., \& Li, X. (2008). Swarm intelligence in optimization. In Swarm Intelligence: Introduction and Applications (pp. 43-85). Springer International Publishing.

Bose, G. K., \& Pain P. (2018). Metaheuristic approach of multi-objective optimization during EDM process. International Journal of Mathematical, Engineering and Management Sciences. 3(3), 301314.

Bramer, M., Ellis, R., \& Petridis, M. (2010). Group counseling optimization: a novel approach. In Research and Development in Intelligent Systems (pp. 195-208). Springer International Publishing.

Cerny, V. (1985). Thermo dynamical approach to the traveling salesman problem: an efficient simulation algorithm. Journal of Optimization Theory and Applications, 45(1), 41-51.

Dai, C., Zhu, Y., \& Chen, W. (2007). Seeker optimization algorithm. In Computational Intelligence and Security (pp. 167-276). Springer International Publishing.

Davies, N. B., \& Krebs, J. (1993). An introduction to behavioral ecology. Third Edition. Blackwell Publishing, Oxford, UK.

Du, H., Wu, X., \& Zhuang, J. (2006). Small-world optimization algorithm for function optimization. In International Conference on Natural Computation ICNC 2006. 'Advances in Natural Computation'. Springer, 264-273.

Eita, M. A., \& Fahmy, M. M. (2014). Group counseling optimization. Applied Soft Computing, 22, 585604.

Erol, O. K., \& Eksin, I., (2006). A new optimization method: big bang-big crunch, Advances in Engineering Software, 37(2), 106-111.

Fogel, L. J., Owens A. J., \& Walsh, M. J. (1966). Artificial intelligence through simulated evolution. Oxford, England: John Wiley \& Sons.

Formato, R. A. (2007). Central force optimization: A new meta-heuristic with applications in applied electromagnetics, Progress in Electromagnetics Research, 77, 425-491.

Gandomi, A. H. (2014). Interior search algorithm (ISA): a novel approach for global optimization, ISA Transaction, 53(4), 1168-1183.

Gao, W. F., Liu, S. Y., \& Huang, L. L. (2013). A novel artificial bee colony algorithm based on modified search equation and orthogonal learning. IEEE Transactions on Cybernetics, 43(3), 1011-1024.

Gao, W., \& Liu, S. (2011). Improved artificial bee colony algorithm for global optimization. Information Processing Letters, 111(17), 871-882.

Gao, W., Liu, S., \& Huang, L. (2012). A global best artificial bee colony algorithm for global optimization. Journal of Computational and Applied Mathematics, 236(11), 2741-2753.

Geem, Z. W., Kim, J. H., \& Loganathan, G. V. (2001). A new heuristic optimization algorithm: harmony search. Simulation, 76(2), 60-68.

Ghorbani, N., \& Babaei, E. (2014). Exchange market algorithm, Applied Soft Computing, 19, 177-187.

Gogna, A., \& Tayal, A. (2013). Metaheuristics: review and application. Journal of Experimental \& Theoretical Artificial Intelligence, 25(4), 503-526. 
International Journal of Mathematical, Engineering and Management Sciences

Vol. 4, No. 2, 471-488, 2019

https://dx.doi.org/10.33889/IJMEMS.2019.4.2-039

Hatamlou, A. (2013). Black hole: a new heuristic optimization approach for data clustering. Information Sciences, 222, 175-184.

He, G., \& Huang, N. J. (2012). A modified particle swarm optimization algorithm with applications. Applied Mathematics and Computation, 219(3), 1053-1060.

Karaboga, D., \& Basturk, B. (2007). A powerful and efficient algorithm for numerical function optimization: artificial bee colony (ABC) algorithm. Journal of Global Optimization, 39(3), 459-471.

Kashan, A. H. (2011). An efficient algorithm for constrained global optimization and application to mechanical engineering design: League championship algorithm (LCA). Computer-Aided Design, 43(12), 1769-1792.

Kaveh, A. (2014). Colliding bodies optimization. In Advances in Meta-Heuristic Algorithms for Optimal Design of Structures (pp. 195-232). Springer International Publishing.

Kaveh, A., \& Farhoudi, N. (2013). A new optimization method: dolphin echolocation. Advances in Engineering Software, 59, 53-70.

Kaveh, A., \& Khayatazad, M. (2012). A new meta-heuristic method: ray optimization. Computers and Structures, 112-113, 283-294.

Kaveh, A., \& Khayatazad, M. (2013). Ray optimization for size and shape optimization of truss structures. Computers \& Structures, 117, 82-94.

Kaveh, A., \& Mahdavi, V. R. (2014). Colliding bodies optimization: a novel meta-heuristic method. Computers \& Structures, 139, 18-27.

Kaveh, A., \& Nasrollahi, A., (2014). A new hybrid meta-heuristic for structural design: ranked particles optimization. Structural Engineering and Mechanics, 52(2), 405-426.

Kaveh, A., \& Talatahari, S (2010). A novel heuristic optimization method: charged system search. Acta Mechanica, 213(3-4), 267-289.

Kaveh, A., Bakhshpoori, T., \& Afshari, E. (2014). An efficient hybrid particle swarm and swallow swarm optimization algorithm. Computers \& Structures, 143, 40-59.

Kirkpatrick, S., Gelatt, C. D., \& Vecchi, M. P. (1983). Optimization by simulated annealing. Science, 220(4598), 671-680.

Kumar, V., Chhabra, J., \& Kumar, D. (2015). A hybrid approach for data clustering using expectationmaximization and parameter adaptive harmony search algorithm. In: Proceedings of International Conference on Future Computational Technologies, pp. 61-67.

Kumar, V., Chhabra, J., \& Kumar, D. (2017). Grey wolf algorithm-based clustering technique. Journal of Intelligent Systems, 26(1), 153-168.

Liang, Y., \& Yu, H. (2005). PSO-based energy efficient gathering in sensor networks. In International Conference on Mobile Ad-hoc and Sensor Networks (pp. 362-369). Springer, Berlin, Heidelberg.

Mann, P. S., \& Singh, S. (2017). Improved artificial bee colony metaheuristic for energy-efficient clustering in wireless sensor networks. Artificial Intelligence Review, 1-26, DOI: 10.1007/s10462-0179564-4

Mirjalili, S. (2015). The ant lion optimizer. Advances in Engineering Software, 83, 80-98.

Mirjalili, S., \& Lewis, A. (2016). The whale optimization algorithm. Advances in Engineering Software, 95, 51-67.

Mirjalili, S., Gandomi, A. H., Mirjalili, S. Z., Saremi, S., Faris, H., \& Mirjalili, S. M. (2017). Salp swarm algorithm: a bio-inspired optimizer for engineering design problems. Advances in Engineering Software, 114, 163-191. 
International Journal of Mathematical, Engineering and Management Sciences

Vol. 4, No. 2, 471-488, 2019

https://dx.doi.org/10.33889/IJMEMS.2019.4.2-039

Mirjalili, S., Mirjalili, S. M., \& Lewis, A. (2014). Grey wolf optimizer. Advances in Engineering Software, $69,46-61$.

Moghaddam, F. F., Moghaddam, R. F., \& Cheriet, M. (2012). Curved space optimization: a random search based on general relativity theory. arxiv preprint arXiv:1208.2214.

Moosavian, N., \& Roodsari, B. K. (2014a). Soccer league competition algorithm, a new method for solving systems of nonlinear equations. International Journal of Intelligence Science, 4(1), 7-16.

Moosavian, N., \& Roodsari, B. K. (2014b). Soccer league competition algorithm: a novel meta-heuristic algorithm for optimal design of water distribution networks. Swarm and Evolutionary Computation, $17,14-24$.

Neri, F., Iacca, G., \& Mininno, E. (2013). Compact optimization. In Handbook of Optimization (pp. 337364). Springer, Berlin, Heidelberg.

Pramy, F. A. (2018). An approach for solving fuzzy multi-Objective linear fractional programming problems. International Journal of Mathematical, Engineering and Management Sciences, 3(3), 280293.

Ramezani, F., \& Lotfi, S. (2013). Social-based algorithm (SBA). Applied Soft Computing, 13(5), 28372856.

Rashedi, E., Nezamabadi, H., \& Saryazdi, S. (2009). GSA: a gravitational search algorithm. Information Science, 179(13), 2232-2248.

Rechenberg, I. (1973). Evolution strategy: optimization of technical systems by means of biological evolution. Fromman-Holzboog, Stuttgart, 104, 15-16.

Sadollah, A., Bahreininejad, A., Eskandar. H., \& Hamdi. M., (2013). Mine blast algorithm: a new population based algorithm for solving constrained engineering optimization problems, Applied Soft Computing, 13(5), 2592-2612.

Saremi, S., Mirjalili, S., \& Lewis, A. (2017). Grasshopper optimization algorithm: theory and application. Advances in Engineering Software, 105, 30-47.

Simon, D. (2008). Biogeography-based optimization. IEEE Transactions on Evolutionary Computation, 12(6), 702-713.

Storn, R., \& Price, K. (1997). Differential evolution a simple and efficient heuristic for global optimization over continuous spaces, Journal of Global Optimization, 11(4), 341-359.

Tan, Y., \& Zhu, Y. (2010, June). Fireworks algorithm for optimization. In International Conference in Swarm Intelligence (pp. 355-364). Springer, Berlin, Heidelberg.

Wang, J., Ren, X. L., Shen, Y. L., \& Liu, S. Y. (2010, January). A remote wireless sensor networks for water quality monitoring. In Innovative Computing \& Communication, 2010 International Conference on and Information Technology \& Ocean Engineering, 2010 Asia-Pacific Conference on (CICC-ITOE) (pp. 7-12). IEEE

Webster, B., \& Bernhard, P, (2003). A local search optimization algorithm based on natural principles of gravitation", In Proceedings of the International Conference 2003, on Information and Knowledge Engineering (IKE'03), 255-261.

Wilson, E. O. (2000). Sociobiology: The New Synthesis. 25th Anniversary Editions. The Belknap Press of Harvard University Press Cambridge, Massachusetts and London, England.

Yang, X.-S. (2010). Firefly algorithm, In Engineering Optimization (pp. 221-230). Wiley Online Publishing. 
International Journal of Mathematical, Engineering and Management Sciences

Vol. 4, No. 2, 471-488, 2019

https://dx.doi.org/10.33889/IJMEMS.2019.4.2-039

Yang, X. S., \& Deb, S. (2009). Cuckoo search via Levy flights. In: Nature \& biologically inspired computing (NaBIC), World Congress, 210-214.

Yang, X.-S. (April-2010). A new meta-heuristic bat-inspired algorithm, in: nature inspired cooperative strategies for optimization (NISCO 2010), Studies in Computational Intelligence, Springer Berlin, 284, $65-74$.

Yao, X., Liu, Y., \& Lin, G. (1999). Evolutionary programming made faster. IEEE Transactions on Evolutionary Computation, 3(2), 82-102.

(c) (i) Original content of this work is copyright () International Journal of Mathematical, Engineering and Management Sciences. All rights reserved. Except of uses under a Creative Commons Attribution 4.0 International (CC BY 4.0) license at https://creativecommons.org/licenses/by/4.0/ 